\title{
Minimally invasive thoracic surgery in lung cancer: respecting oncologic principles is the key
}

\author{
Diego Gonzalez-Rivas $^{1,2}$, William Guido-Guerrero ${ }^{3}$, Albert Bolaños-Cubillo ${ }^{3}$ \\ ${ }^{1}$ Department of Thoracic Surgery, Coruña University Hospital and Minimally Invasive Thoracic Surgery Unit (UCTMI), Coruña, Spain; \\ ${ }^{2}$ Department of Thoracic Surgery, Shanghai Pulmonary Hospital, Tongji University School of Medicine, Shanghai 200433, China; ${ }^{3}$ Department of \\ Thoracic Surgery, Rafael Ángel Calderón Guardia Hospital, San José, Costa Rica \\ Correspondence to: William Guido-Guerrero. Department of Thoracic Surgery, Rafael Ángel Calderón Guardia Hospital, San José, Costa Rica. \\ Email: guido.william@gmail.com. \\ Provenance: This is an invited Editorial commissioned by Section Editor Song $\mathrm{Xu}, \mathrm{MD}, \mathrm{PhD}$ (Department of lung cancer surgery, Tianjin Medical \\ University General Hospital; Tianjin Key Laboratory of Lung Cancer Metastasis and Tumor Microenvironment, Lung Cancer Institute, Tianjin, \\ China). \\ Comment on: Boffa DJ, Kosinski AS, Furnary AP, et al. Minimally Invasive Lung Cancer Surgery Performed by Thoracic Surgeons as Effective as \\ Thoracotomy. J Clin Oncol 2018;36:2378-85.
}

Submitted Nov 30, 2018. Accepted for publication Dec 10, 2018.

doi: $10.21037 / \mathrm{atm} .2018 .12 .20$

View this article at: http://dx.doi.org/10.21037/atm.2018.12.20

The use of thoracoscopy is evolving every day and is improving daily including lung cancer management, beginning with multiport simple procedures to single port highly advanced surgeries (1). Faster recovery rate, less postoperative pain, better cosmetic results, reduction in hospital stay and less morbidity are known advantages of video-assisted thoracic surgery (VATS) $(2,3)$.

One of the biggest controversies that today is debated worldwide is the oncological outcome of VATS lobectomies when it is compared to open approaches. Detection of unsuspected lymph node metastases during the final histopathologic evaluation of a resected surgical piece is determinant for adjuvant treatment, prognosis and survival. This nodal upstaging in lung cancer is dependent of a complete lymphadenectomy or a sampling of lymph nodes (4). In general, more than 10 lymph nodes sampled were associated with better cancer specific and overall survival for stage I (5). One study found that nodal upstaging was lower after VATS than after open lobectomy for stage I non-small cells lung cancer, suggesting a better oncologic outcome for the open approach in lung cancer (6).

It is only expectable, that as a result of the growth in experience in minimally invasive lung cancer surgery the lymphadenectomy achieved by this approach will be as complete as the one obtained through thoracotomy, since the oncologic principles are the same the procedure performed only is different in the approach, not in the lymphadenectomy expected according to current guidelines.

The article by Boffa $e t$ al. is a retrospective study that compares VATS lobectomy with open lobectomy, for stage I lung cancer in patients older than 65 years of age. They used the Society of Thoracic Surgeons General Thoracic Surgery Database to determinate the long-term efficacy of lobectomy for stage I lung cancer performed by boardcertified thoracic surgeons (7). At the end, they concluded that 4-year survival of patients with stage I lung cancer managed using the VATS approach performed by boardcertified thoracic surgeons does not seem to be inferior to that of patients undergoing thoracotomy.

They analyzed a big population for a total of 10,597 patients between 2002 and 2013, 41.97\% patients underwent thoracotomy, and $58.03 \%$ underwent VATS (7). It is important to comment the authors included far greater detail on patient health like pulmonary function, performance status, malnutrition and concomitant diseases; the preoperative staging evaluation with imaging and invasive mediastinal evaluation; all of that to reduce study bias.

The nodal upstaging in this study favors the open approach, but in the end there was no significant difference in survival after resection (7). If the problem of VATS was a poor lymph node dissection, one would assume that 
some of these patients would be under staged because undetected lymph node metastases that were not removed would result in reduced survival after VATS given that the prognosis after resection for NSCLC decreases with more advanced disease (6). Despite this, there are recent reports indicating safety of lymph node sampling during VATS lobectomy (8); VATS resection for lung cancer does not compromise oncologic efficacy (9) and reports of no statistical difference in three year overall, disease-free (treated recurrence), and cancer specific survival between thoracoscopic versus open thoracotomy lobectomies (10).

A recent study with similar population, concluded that VATS lobectomy for NSCLC is associated with better postoperative outcomes, but similar long-term survival, compared to open lobectomy among older adults, even after controlling for surgeon experience (11).

Although the authors tried that the study had less biases, it has several limitations. One obvious problem is the age of the population, they restricted the age to older than 65 years old, and so the data cannot be applicable to younger patients (7).

As a retrospective observational study, the original records were not designed for the study and there can be hidden biases and confounding factors that can affect the outcome because the data was recorded in the past; for example, the histology of the tumors was not recorded for the years of study, so we cannot compare information with different types of lung tumors (7). In the same way, because of changes in the standard technique resection, using open surgery in the first years of the study, then multiport VATS lobectomies and in the last years de development of uniportal VATS resections, they do not make difference between uniportal VATS and multiport approaches, they only compare the open approaches and VATS with no differentiations of the VATS technique.

If we want to solve the actual debate whether VATS is better than open lobectomy, we need a randomized controlled trial (12); but for now, the study of Boffa et al., with a good analytical approach, helped us to see that survival of stage I lung cancer using VATS lobectomy does not seem to be inferior to that of patients undergoing open thoracotomy (7).

One question that arises is if we could obtain similar results in lung cancer patients with stage 2 and $3 \mathrm{~A}$. The fact is, we already know that a complete lymphadenectomy is feasible and safe by VATS (13), how thorough it is it will only depend in the experience of the surgeon. As VATS become the procedure of choice for the majority of thoracic surgeons and with the expansion of minimally invasive thoracic surgery, specially uniportal VATS, thoracic surgeons will become more comfortable operating in advance cases and if oncologic principles are respected, results should not differ from the ones obtained by open approach.

\section{Acknowledgements}

None.

\section{Footnote}

Conflicts of Interest: The authors have no conflicts of interest to declare.

\section{References}

1. Guido-Guerrero W, Bolaños-Cubillo A, González-Rivas D. Single-port video-assisted thoracic surgery (VATS)advanced procedures \&amp; update. J Thorac Dis 2018;10:S1652-61.

2. Harris CG, James RS, Tian DH, et al. Systematic review and meta-analysis of uniportal versus multiportal videoassisted thoracoscopic lobectomy for lung cancer. Ann Cardiothorac Surg 2016;5:76-84.

3. Jawitz OK, Wang Z, Boffa DJ, et al. The differential impact of preoperative comorbidity on perioperative outcomes following thoracoscopic and open lobectomies. Eur J Cardiothorac Surg 2017;51:169-74.

4. Ellis MC, Diggs BS, Vetto JT, et al. Intraoperative oncologic staging and outcomes for lung cancer resection vary by surgeon specialty. Ann Thorac Surg 2011;92:1958-63.

5. David EA, Cooke DT, Chen Y, et al. Does Lymph Node Count Influence Survival in Surgically Resected Non-Small Cell Lung Cancer? Ann Thorac Surg 2017;103:226-35.

6. Licht PB, Jørgensen OD, Ladegaard L, et al. A national study of nodal upstaging after thoracoscopic versus open lobectomy for clinical stage I lung cancer. Ann Thorac Surg 2013;96:943-9; discussion 949-50.

7. Boffa DJ, Kosinski AS, Furnary AP, et al. Minimally Invasive Lung Cancer Surgery Performed by Thoracic Surgeons as Effective as Thoracotomy. J Clin Oncol 2018;36:2378-85.

8. Gonfiotti A, Bertani A, Nosotti M, et al. Safety of lymphadenectomy during video-assisted thoracic surgery 
lobectomy: analysis from a national database†. Eur J Cardiothorac Surg 2018. [Epub ahead of print].

9. Berry MF, D'Amico TA, Onaitis MW, et al. Thoracoscopic approach to lobectomy for lung cancer does not compromise oncologic efficacy. Ann Thorac Surg 2014;98:197-202.

10. Paul S, Isaacs AJ, Treasure T, et al. Long term survival with thoracoscopic versus open lobectomy: propensity matched comparative analysis using SEER-Medicare database. BMJ 2014;349:g5575.

Cite this article as: Gonzalez-Rivas D, Guido-Guerrero W, Bolaños-Cubillo A. Minimally invasive thoracic surgery in lung cancer: respecting oncologic principles is the key. Ann Transl Med 2018;6(Suppl 2):S125. doi: 10.21037/atm.2018.12.20
11. Ezer N, Kale M, Sigel K, et al. Outcomes after Videoassisted Thoracoscopic Lobectomy versus Open Lobectomy for Early-Stage Lung Cancer in Older Adults. Ann Am Thorac Soc 2018;15:76-82.

12. Allen MS. Video-assisted thoracoscopic surgery versus open lobectomy for lung cancer: time for a randomized trial. Eur J Cardiothorac Surg 2017;51:175.

13. Shao $W$, Liu J, Liang $W$, et al. Safety and feasibility of video-assisted thoracoscopic surgery for stage IIIA lung cancer. Chin J Cancer Res 2014;26:418-22. 